\title{
Quality Improvement in Management System: A Case Study of CCTEC Company China
}

\author{
Giron Kamonja1*, Yan Liang1, Muhammad Tayyab Sohail' ${ }^{2}$, Shahzad Ahmad Khan ${ }^{1}$ \\ ${ }^{1}$ School of Economic and Management, China University of Geosciences (Wuhan), Wuhan, China \\ ${ }^{2}$ School of Public Administration, China University of Geosciences (Wuhan), Wuhan, China \\ Email: gkamonja2001@yahoo.fr, tayyabsohail@yahoo.com
}

Received 21 March 2014; revised 8 April 2014; accepted 15 April 2014

Copyright (C) 2014 by authors and Scientific Research Publishing Inc.

This work is licensed under the Creative Commons Attribution International License (CC BY). http://creativecommons.org/licenses/by/4.0/

(c) (i) Open Access

\begin{abstract}
Certain difficulties are inherent in the implementation of the improvement of the quality of service, particularly in the Design Management Department. There is often a difference on the issue of translating vision between senior management and Design Department for service improvement into effective, operational QI programs. Middle managers have a key role to play, but often they are overlooked which leads to undermining their efforts to improve the quality programs offered by senior management. This paper describes the first phase of a $\mathrm{PhD}$ research project to determine and develop the role of middle management in successful implementation of quality management programs. A framework for quality improvement implementation, including key issues of importance to middle managers regarding their proactive involvement in QI, is suggested. Finally, the initial implementation of the model in a company is discussed.
\end{abstract}

\section{Keywords}

Quality Improvement (QI), Design Management Department (DMD), Middle Manager (MM)

\section{Introduction}

List of literatures about field QI is non exhaustive. Many studies try to show the advantages given by the effectiveness of QI implementation [1] in the production sector. Unfortunately, many companies are still at a long off practice of this; especially CCTEC Co. Ltd. It is found that nature of management style to this company de-

${ }^{*}$ Corresponding author.

1st Authors: Giron Kamonja, Muhammad Tayyab Sohail; 2nd Author: Yan Liang; 3rd Author: Shahzad Ahmad Khan.

How to cite this paper: Kamonja, G., et al. (2014) Quality Improvement in Management System: A Case Study of CCTEC Company China. American Journal of Industrial and Business Management, 4, 209-216.

http://dx.doi.org/10.4236/ajibm.2014.44028 
serves to revise. The lack of leadership [2] at the executive level is causing the derailment of the production process in particular Design Department. That is why Juran [3] attributes the quality excellence of the Japanese companies to senior managers' commitment to quality. Therefore, it needs to see the commitment of middle managers [4] carefully in the performance of their duties. They often have inappropriate MM compared to that required by the program of improving the quality behavior [5]. Indeed, coaching staff scrupulously ensures the design department is useful for the effective implementation of the model [6] that was designed.

\subsection{Project Background and Purpose}

This research project is to improve the traceability of production with the intention of developing manufacturing competitiveness [7] within the company. The major concern is to determine the effective way likely, Cathy Burgess [8] to encourage more middle managers for a better product design. In this sense, this latter in fact requires the effective implementation of improvement determined by the company of which design department is responsible for implementing the program. This means that the program will be in vain when the staff of the department of design does not take it seriously. QI program will not be achieved as expected, even the staff working correctly when it has no Competencies required for the job in question, as stated Eric Chong [9] Assume now that the agents of the department of design work as it should; is their deployment effort directly affecting the image of the company's product? We try to answer through this research the question raised above. The leaders of the company are obliged to improve the quality of their companies' products before tough competition today. Therefore, the appropriate leadership which the company needs to facilitate its integration in the competition must be implemented in order to succeed the objectives if leaders adopt the three faces of integrity as developed by David C. Bauman [10].

The company must remain competitive against its opponents. Yet its competitiveness depends on the quality of its product that proposed to be sold in the competitive market. The client plays the role of a judge, and he will purchase the product according to his taste, choice and preference towards market goods and services. When the company is able to hold the weight of the competition, it means that it is competitive; it is up to cope with the competitive bid. It finally made a profit owing to competitive advantage. In this sense, it can be said that the convergence of efforts on QI undertaken by middle managers [11] can contribute to the improvement of the turnover of the company in case it remains competitive in the market.

\subsection{Definition of Quality Improvement (QI)}

The definition of quality improvement is complicated. It depends primarily on the meaning of "quality". It is a word that has multidimensional aspects. As Biggs (2001) [12] points out, "quality can be defined as an outcome, property or process". Therefore, it is hardly surprising that the phrase "Quality Improvement" has been given several definitions. For businesses and managers, the annual improvement of quality can be measured by the absence of defects; it can also be evaluated by the degree of customer satisfaction with a product's characteristics and features. Annual Quality Improvement [13] [14] does not mean the result of taking responsibility but it is also the result of a radical change in the way which manages the company previously; this is to say, the change in company culture.

\section{Quality Improvement Effect in Production Process}

According Juran [15], QI have effect on the following parameters:

- Productivity: The output per person-hour becomes higher.

- Cycle time: The time required to carry out processes.

- Human safety: Many projects improve human safety through error proofing, fail-safe designs, and so on.

- The environment: IQ effect does not exclude the protection of the environment; on the contrary, it reinforces the improvement of the environment through the reduction of toxic emission.

Given that quality improvement is still in the annual work plan of the company CCTEC Co. Ltd., obtained performance result related activities converging at the quality improvement. It is indeed necessary to identify all present opportunities to motivate middle managers [8] for that quality improvement is real within the company. The strengthening of capacity of actor's production using a series of training should be featured in the annual work program of the company. Senior management of CCTEC Co. Ltd., does not subscribe to a particular philosophy of quality, but encourages staff to develop their own approach based on the principle of total quality 
management (TQM) and Continuous Improvement Quality [13] (CQI). We choose the appropriate term Quality Improvement (QI) to describe different approaches for the improvement within the company. Middle managers [16] are mainly involved in the process of looking for the improvement of quality. They are technicians which are able to meet the specific needs identified in the organization. The objective of enhancing the participation of middle managers at CCTEC Co. Ltd. as proposed by Manab Thakur [16] [17] is to achieve:

- The implementation of thorough IQ which performance will be estimated by the organization achieved objective.

- Increased participation in IQ according to the progressive implementation of QI program worked by the quality manager.

\section{Project Implementation}

\subsection{Baseline Data Collection}

Research method [18] employed for data collecting was via survey. Indeed, this was conducted within the company CCTEC Co. Ltd. A questionnaire according to the requirement of Research Methods [19] distributed to middle managers from Department Design to collect their views on Quality Improvement. The survey instrument was distributed electronically via online survey tool to all middle managers in the organization. Classification questionnaires and a similar response diversified the group discussion. The treatment of results concerned the thorough analysis of the literature in the field of quality improvement [4] [13] and implementation of QI program in the production process. A factor analysis identified four factors that supported the priority design of research: organization and role [20], understanding of QI [21] [22], involvement in QI [8] [11] and commitment in QI.

Each middle manager responded to the questionnaire issued with a participation rate of $100 \%$. The validity of the results was established by piloting the questionnaire and discussing the results with respondents. These validated results have enabled a state of place on the IQ. The synthesis of these results and lessons learned in the literature review leads to the conclusion based on a perspective of improving IQ in the future. The development of a new model of the quality improvement within CCTEC Co. Ltd was inspired.

The literature review on one hand highlights some positive elements that can improve the QI program, the results of the survey on the other hand showed the expectations of middle managers on improving program quality [4] [5]. The comparison of these two programs IQ raised a strong correlation as shown in Table 1 below.

The initiative for the implementation of QI is at the end of the initial assessment of the company. The study results of the survey carried has identified two favorable tools to achieve the objectives QI. The first one is the "evolutionary model of continuous improvement behavior" (Bessant, Cassyn \& Gallagher, 2001) [23]. And the second is an internal quality improvement progress report using Criteria derived from the requirements for the CCTEC Organizational requirements. On the scale of 1 - 5 used in the Bessant et al. model, the CEO and researcher agreed that the company scored a 2 . When using the internal model, which is rated departments out of 5 , each department was scored individually according their progress and internal requirements for accreditation and the company QI programs. When evaluating the project start, 50\% of departments have received 2 or less.

Table 1. Comparison of findings from the QI related literature and middle manager survey results.

\begin{tabular}{|c|c|}
\hline Literature & Survey Feedback \\
\hline Understanding of definitions, goals and targets & Clarify Company \& QI goals \\
\hline $\begin{array}{l}\text { QI Framework/Approach should be simple, flexible and link } \\
\text { to supervisor/ staff values and culture }\end{array}$ & Simplify QI process and Clarify QI goals \\
\hline Program should be surely successful & Improve feedback and tangible proofs of improvements \\
\hline Top Management commitment and support & $\begin{array}{l}\text { reinforce senior management and support and allocate } \\
\text { appropriate resources }\end{array}$ \\
\hline Implement systems in the working environment & $\begin{array}{l}\text { Improve inter-departmental activities, teamwork, group work, } \\
\text { promote fighting spirit and communication }\end{array}$ \\
\hline $\begin{array}{c}\text { Make QI program involving the participation middle } \\
\text { management role }\end{array}$ & $\begin{array}{l}\text { Empower middle managers, make their accountabilities } \\
\text { clear and encourage initiative and skill building }\end{array}$ \\
\hline $\begin{array}{l}\text { Give Middle management access to } \\
\text { decision making in meeting }\end{array}$ & $\begin{array}{l}\text { Make clear company goals, improve company communication, } \\
\text { promote access to senior management }\end{array}$ \\
\hline Educate, train, inform & Improve QI skills, knowledge, information and confidence \\
\hline
\end{tabular}


The objective of this research was: $80 \%$ of departments have three or more during the re-evaluation at the end of the project.

\subsection{Structure of a Middle Management Participation Model}

The combination of results from focus groups, the survey of middle managers as well as the review of the literature has developed a model of middle management-led QI program.

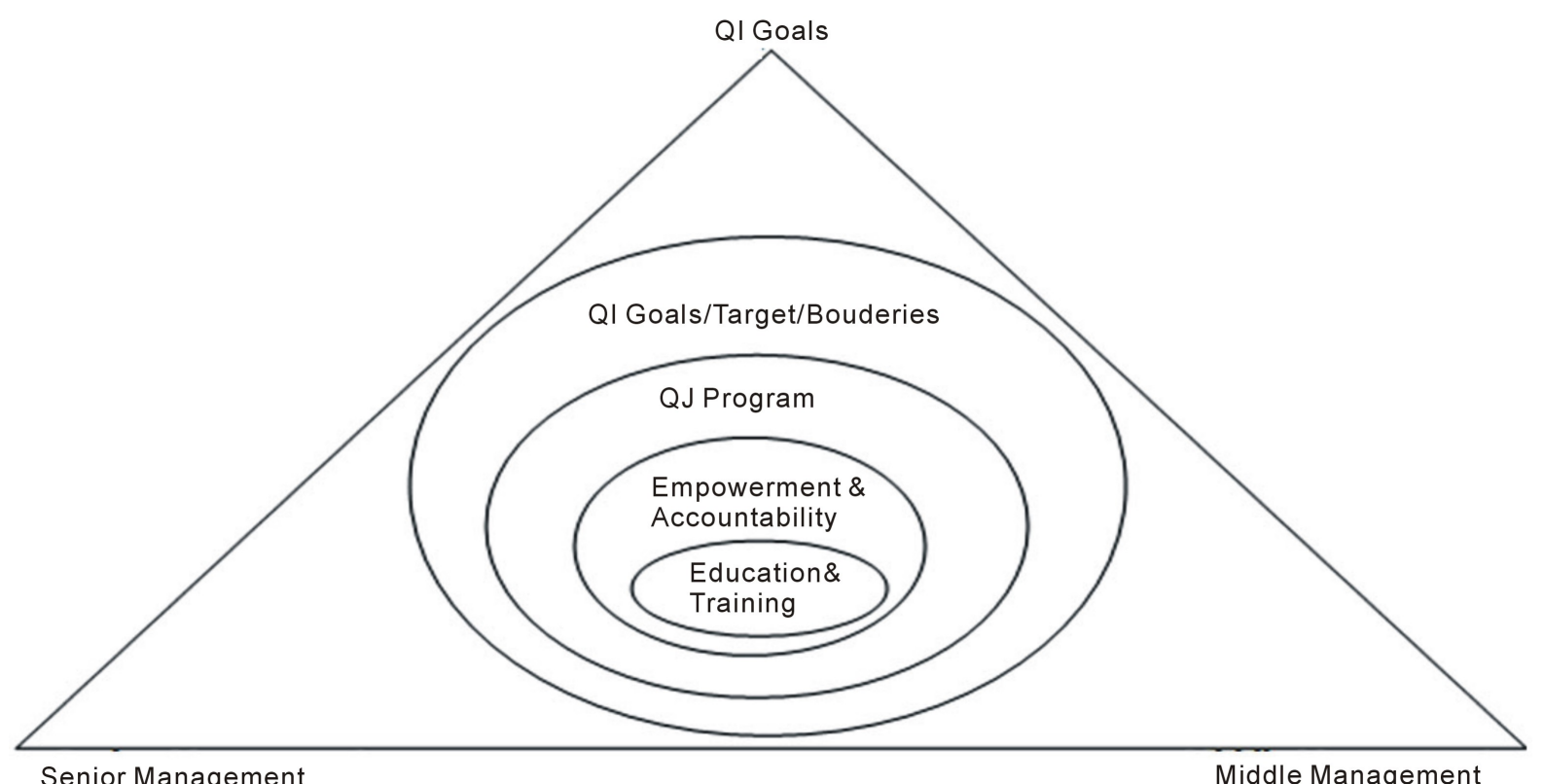

The model consists of five elements:

1) Senior Management (SM) Commitment \& Support [24]

- SM works closely with middle managers in the framework of the place setting of the structure and the QI process.

- SM gives full power to middle managers to participate better in improvement activities.

- SM creates, manages improvement culture and encourages innovation to achieve improvement goals and reward appropriate behavior.

- SM defines and establishes the link between the strategic plan / business and the QI program.

- SM undertakes to regularly (every six months) review the advancement of the QI program with middle managers.

2) QI Goals [25], Targets, Boundaries and Approach clearly defined by SM and MM

- SM \& MM together define not only the QI program, but also the expected goal of this list.

- SM \& MM decided the objectives and targets of the QI program that determine strategic and business plans, values and interests of staff.

- SM \& MM have agreed on the structure of QI and model to be applied.

- QI priorities, tools and methods to be adapted «local» needs and values.

- MM and other staff make operational QI.

3) MM set up a QI Group/Committee to drive the QI Program [5] [16]

- MM IQ group sets up the process of communicating with the rest of the organization due to deficiency with asymmetry of information; that is to say the flow of information both horizontally and vertically.

- MM IQ group initiates a series of short-term QI projects across the organization.

- MM IQ group develops the process that simplifies IQ data collection and reporting and facilitates the completion of the IQ cycle.

- MM QI Group encourages t participants in the QI project to recognize the flow on effects of their activities throughout the organization. 
- QI Group regularly reviews the progress and achievements with senior management. 4) SM \& MM agree MM role accountability and empowerment for QI [26]

- SM \& MM establish clear goals and give reward to MM because of the participation in QI projects and especially the reinforcement of IQ culture in different services.

- SM empowers MM to make decisions and undertake innovative actions to achieve the IQ goals.

- SM ensures access to information necessary for MM to monitor and improve services; it can also optimize the transmission of relevant information to senior management.

5) SM [24] provides resources and opportunities for QI education, training and information to all Staff

- MM IQ group recommends the topic of the organizing education program for staff to participate in QI projects.

- Ensure all of staff has access to QI education and training which covers basic information, QI tools and techniques;

- IQ Education and Training must be provided at the beginning of QI project it was the subject of the staff request for there is skill to deal the renovation IQ goals required.

\section{Implementation of the Model}

The implementation of the model was the result of the work of "QI review group”. Twelve frames mean that 33\% of the total frameworks had focused on the results of the investigation. A steering committee was subsequently established after their examination of these results and deep investigation. The steering committee is responsible for overseeing the implementation of the program of quality improvement.

The committee does not work alone, it collaborates with key staff. It would ensure un-bias in taking the unilateral decision. In this sense, the advice of the Chief Executive and the experts are needed to fix the strategic plan and related budget in the context of the implementation of the QI program itself.

The steering committee of service improvement, as its name suggests, it is concerned to the first instance improving the quality of the organization [16] [20]. He tries to bring in the second time for clarification on the role and function of the committee itself.

Receiving appropriate advice helped to develop the work of the committee. The development of the labor process group urged stakeholders to add explicit information to enhance the model [23] itself. The committee of Service Improvement decided to convene a meeting at the beginning of each week. This weekly meeting can evaluate the activities done during the previous week also identify those to be achieved during the current week. A working method was set to optimize the work of the committee. This method involves setting up three working groups responsible for: communication, development of the activity of IQ and education IQ. Each group has a duty to prepare its terms of reference and working strictly in the framework of term valid reference.

\section{Role of Service Improvement Committee}

The role of Service Improvement Committee consists of promotion and stimulation of the improvement of activities in Design Department of CCTEC Co. Ltd. Indeed, it will:

1) Clarify agents DMD activities which need improvements;

2) Develop and implement a systematic approach to monitor the progress of QI program in CCTEC Co. Ltd, and provide assistance to the team during the realization of activities;

3) Review current practices, identify deficiencies in the service provision, manage and provide the prospects for improvement;

4) Ensure the effective participation of all relevant stakeholders in activities to improve services;

5) Ensure the quality improvement (QI) activities that meet standard criteria and advise staff on the importance of cycle IQ;

6) Allocate material and financial resources to enhance and support all initiatives of improvement;

7) Receive all comments from staff regarding the implementation of IQ tasks, and draw the conclusion on the educational needs of the IQ improvement activities.

\section{Conclusions}

We can say that the current situation of the company remains unchanged. Middle managers are underemployed, i.e. they cannot act in their own way without consulting previously the supervisor opinion. But this latter is often 
unavailable or in mission. This constitutes a blocking factor in the implementation IQ. This comes down to say it is great time to change the work process in DMD. The leaders of the company especially DMD Manager should leave free his collaborators to conduct their work as it should. He should have confidence in their experience and skills. Thus, we estimate that these middle managers should proceed directly to both design study and the procedure of the realization in accordance to the company project. We judge it is not necessary to wait for the correction upstream regarding the technicians' work in DMD; however, the downstream correction is unavoidable. A coercive measure is indeed necessary in the usual process work of DMD team. The application of model proposed by this research will enable for increasing further in value the middle managers skills. Valorization of their skills thereafter will have a repercussion both on the image and on the products quality.

This document sums up the survey cum-inventory briefly IQ. The investigation described the current situation in the QI process CCTEC Co. Ltd in particular DMD. Examination of the results gathered during the investigation led to identify problems that impede IQ. These problems are among others:

- Major problems are faced by middle managers in the implementation of IQ.

- Insufficient core motivating factors for middle managers in the framework of implementation of the strategic plan.

- There is also a lack of autonomy of middle managers on project management within the QI program. The progress made in the implementation of the model is from the discussion on the following points:

- IQ Service Improvement Committee activities;

- Senior management role and feedback;

- Feedback from staff analysis;

- Vision of the experts in terms of staff participation in QI.

Up to now, we can say that middle managers [27] can probably assume responsibility for implementing QI program. Information, support and appropriate advice allow all stakeholders to facilitate IQ works undertaken by middle managers. These managers will be armed with a greater sense of ownership and motivation especially regarding IQ. IQ is often not only superficial but also confused by the size and scope of the intervention area. Remains to be verified how it takes effect on the QI success through the organization.

\section{China Continuous Casting Technologies (CCTEC)}

China Continuous casting Technologies (CCTEC) is one of subsidiaries of China Metallurgical Group Corporation (MCC Group). From 2001, CCTEC Co., Ltd was reorganized the excellent technical resources of MCC Group in order to specialize in fields of Continuous casting and Strip processing. Its head office located in Wuhan, Hubei province in the center of China in addition the three branch offices established respectively in Beijing, Shanghai and Ma'anshan. However, the present study is based on the head office in Wuhan. For the purpose of current research, the study focuses on the study of the company in the field of Metallurgy. This case study focuses on CCTEC Co. Ltd, which provides a real opportunity for ensuring in a supply of Small and medium Enterprises (SME) in terms of capital equipment such as caster, moulder. A case study was conducted on CCTEC Co. Ltd within the framework of meeting the objective of the thesis is: "to explore the attitudes of the managers/middle managers of CCTEC Co. Ltd regarding the improvement of DMD practices and comparing them to the competitive company".

\section{Acknowledgements}

I would like to express my special thanks to Professor Yan Liang, Dean of School of Economics and Management for his expert and professional supervision. I also express my gratitude to all my family members in Madagascar especially my mother MARTINE. GIRON Kamonja also attributes a particular recognition to my wife Josie Stella RATSARAHARISOA, and I am pleased to dedicate this article to my daughter KAMONJA Namiantsara.

\section{References}

[1] Douglas, T.J. and Judge Jr., W.Q. (2001) Total Quality Management Implementation and Competitive Advantage: The Role of Structural Control and Exploration. The Academy of Management Journal, 44, 158-169.

[2] Thiagarajan, T. and Zairi, M. (1997) A Review of Total Quality Management in Practice. The TQM Magazine, 9, 270286. http://dx.doi.org/10.1108/09544789710181899 
[3] Juran, J.M. (1993) Made in USA: A Renaissance in Quality. Harvard Business Review, 71, 42-50.

[4] Huy, Q.N. (2002) Emotional Balancing of Organizational Continuity and Radical Change: The Contribution of Middle Managers. Administrative Science Quarterly, 47, 31-69. http://dx.doi.org/10.2307/3094890

[5] Choo, A.S. and Linderman, K.W. (2007) Method and Psychological Effects on Learning Behaviors and Knowledge Creation in Quality Improvement Projects. Management Science, 53, 437-450. http://dx.doi.org/10.1287/mnsc.1060.0635

[6] Veldman, J. and Gaalman, G. (2013) A Model of Strategic Product Quality and Process Improvement Incentives. International Journal of Production Economics, 149, 202-210.

[7] Barnes, J., Bessant, J., Dunne, N. and Morris, M. (2001) Developing Manufacturing Competitiveness within South African Industry: The Role of Middle Management. Technovation, 21, 293-309. http://dx.doi.org/10.1016/S0166-4972(00)00047-X

[8] Burgess, C. (2013) Factors Influencing Middle Managers’ Ability to Contribute to Corporate Entrepreneurship. International Journal of Hospitality Management, 32, 193-201. http://dx.doi.org/10.1016/j.ijhm.2012.05.009

[9] Chong, E. (2013) Managerial Competencies and Career Advancement: A Comparative Study of Managers in Two Countries. Journal of Business Research, 66, 345-353. http://dx.doi.org/10.1016/j.jbusres.2011.08.015

[10] Bauman, D.C. (2013) Leadership and the Three Faces of Integrity. The Leadership Quarterly, 24, 414-426. http://dx.doi.org/10.1016/j.leaqua.2013.01.005

[11] Judge Jr., W.Q. and Stahl, M.J. (1995) Middle-Manager Effort in Strategy Implementation: A Multinational Perspective. International Business Review, 4, 91-111. http://dx.doi.org/10.1016/0969-5931(94)00033-I

[12] Biggs, J. (2001) The Reflective Institution: Assuring and Enhancing the Quality of Teaching and Learning. Higher Education, 41, 221-238. http://dx.doi.org/10.1016/0969-5931(94)00033-I

[13] Somasundaram, S. and Badiru, A.B. (1992) Project Management for Successful Implementation of Continuous Quality Improvement. International Journal of Project Management, 10, 89-101. http://dx.doi.org/10.1016/0263-7863(92)90061-D

[14] Young, J. (1990) Enabling Quality Improvement in British Telecom. Juran Institute, Inc., Wilton.

[15] Juran, J.M. (ed.) (1995) A History of Managing for Quality. ASQC Quality Press, Milwaukee.

[16] Ouakouak, M.L., Ouedraogo, N. and Mbengue, A. (2014) The Mediating Role of Organizational Capabilities in the Relationship between Middle Managers’ Involvement and Firm Performance: A European Study. European Management Journal, 32, 305-318. http://dx.doi.org/10.1016/j.emj.2013.03.002

[17] Thakur, M. (1998) Involving Middle Managers in Strategy Making. Long Range Planning, 31, 732-741. http://dx.doi.org/10.1016/S0024-6301(98)00078-8

[18] Anderson, V. (2004) Research Methods in Human Resource Management. CIPD, London.

[19] Bryman, A. and Bell, E. (2003) Business Research Methods. Oxford University Press, Oxford.

[20] Leste, A. (2014) Organization Roles, Project Management, Planning and Control. 6th Edition, 45-46.

[21] Nasierowsk, W. (2000) Technology and Quality Improvements in Mexican Companies: Some International Comparisons. Journal of Quality Management, 5, 119-137. http://dx.doi.org/10.1016/S1084-8568(00)00016-X

[22] Azaranga, M.R., Gonzalez, G. and Reavill, L. (1998) An Empirical Investigation of the Relationship between Quality Improvement Techniques and Performance-A Mexican Case. Journal of Quality Management, 3, 265-292. http://dx.doi.org/10.1016/S1084-8568(99)80117-5

[23] Bessant, J., Cassyn, S. and Gallagher, M. (2001) An Evolutionary Model of Continuous Improvement Behaviour. Technovation, 21, 67-77. http://dx.doi.org/10.1016/S0166-4972(00)00023-7

[24] Unger, B.N., Kock, A., Gemünden, H.G. and Jonas, D. (2012) Enforcing Strategic Fit of Project Portfolios by Project Termination: An Empirical Study on Senior Management Involvement. International Journal of Project Management, 30, 675-685. http://dx.doi.org/10.1016/j.ijproman.2011.12.002

[25] Linderman, K., Schroeder, R.G. and Choo, A.S. (2006) Six Sigma: The Role of Goals in Improvement Teams. Journal of Operations Management, 24, 779-790. http://dx.doi.org/10.1016/j.jom.2005.08.005

[26] Jonas, D. (2010) Empowering Project Portfolio Managers: How Management Involvement Impacts Project Portfolio Management Performance. International Journal of Project Management, 28, 818-831. http://dx.doi.org/10.1016/j.ijproman.2010.07.002

[27] Ivanova, M. and Torkkel, L. (2013) Managerial Sense Making of Interaction within Business Relationships: A Cultural Perspective. European Management Journal, 31, 717-727. http://dx.doi.org/10.1016/j.emj.2013.07.007 


\section{Acronyms and Abbreviations}

QI: Quality Improvement

DMD: Design Management Department

MM: Middle Manager

TQM: Quality Management

CQI: Continuous Improvement Quality

CCTEC: China Continuous casting Technologies

SM: Senior Management 